\title{
An Analysis of Water Features in Persian gardens; Bagh-e Shahzadeh
}

\author{
Parisa Göker
}

\begin{abstract}
Persian garden is included among the most characteristic and crucial elements in Iranian landscape. The significance of the art of erecting gardens for Iranians can be seen as far as the hot and dry climate of Iran and its water deficiency for plantation are concerned. Water is an important element in Persian garden and it can be purported that gardens would lose their meaning without it. Water is used in garden applications due to its capabilities including life, brightness, cleanliness, light, inertia and motion causing many sensations in the human soul and elevating mental comfort. Furthermore, its various running structures including basins, streams, water creeks and fountains enable mental comfort and technical functions. In this research, water features (pools, fountains, Qanat, waterfalls) situated in Bagh-e Shahzadeh (Shahzadeh Garden), Kerman-Iran, built as the palace garden by Abd-ol Hamid Mirza Nasser-al Dawleh Farman Farma during the rule of Qajars in $1160 \mathrm{AH}$, will be investigated. Design and structural characteristics of water features that survived till present and are situated in the palace gardens will be discussed based on the collected data, and suggestions will be made for the current preservation issues.
\end{abstract}

Index Terms-Historical gardens, Islamic gardens, persian gardens, water.

\section{INTRODUCTION}

Persian Gardens identified as Bagh-e-Irani in Iran, are one of the ancient and historical places in Iran. These gardens may instigate as early as $4000 \mathrm{BCE}$ which the most famous ones can be found in Iran. Currently there are twelve Persian Gardens that authorized as World Heritage Sites. which all of them follow the same prototype [1].

One of the most remarkable elements in Iranian gardens is water usage. Pools are placed in the most important section of backyards or gardens. Numerous pool structures situated in the garden and connection of them with each other by channels ensure coolness and air circulation and the water to flow rhythmically. Building pools on a slightly sloped ground enables water overflow from the pools and formation of small waterfalls. Colorful ceramics are used in general for decorating small conduits surrounding pools. The use of colorful ceramics in pools is another typical feature of Iranian Islamic gardens [2].

\section{METHOD}

In this research, the use of water features in the palace

Manuscript received May 30, 2017; revised August 30, 2017.

Parisa Göker is with the Department of Interior Architecture and Environmental Design, Art and Design Faculty, Bilecik Seyh Edebali University, Bilecik, Turkey (e-mail: parisa.goker@bilecik.edu.tr). landscapes of Persian historical gardens was assessed. In this context, the water features (pools, fountains, Channels and waterfall) situated in Shahzadeh Garden, built as a palace garden by Abd-ol Hamid Mirza Nasser-al Dawleh Farman Farma during the rule of Qajara in 1180 was investigated.

The main material of the research included Shahzadeh Garden and the surveys prepared by the Grand National Assembly of Iran, Department of National Cultural Heritage concerned with the subject and university archives and published and visual materials on the subject made up the principal material of the research. The water features used in Shahzadeh gardens during Qajar period was scrutinized based on these data. The research data were analyzed systematically and assessed and synthesized.

\section{LITERATURE REVIEW}

Traces of garden art in Iran go back to very old ages. Iran prior to Islam developed under the influence of Buddhism in the east, Christianity in the west and Parsee religion in central Iran. According to Zarathustra religion, which was the most powerful and influential religion of the era, the natural factors including soil, water, air and fire are crucial. According to Zarathustra, everyone who sows seeds goes on God's (Mezdisna) path. Mezdisna means God in Zarathustra religion. Religious believes changed after Islam however love of nature continued its existence in Iran until today. Tree planting, garden creation and love of flowers are based on this old philosophy. Hence, magnificent palaces and gardens were structured in Iran by the thrones throughout historical ages. There are many palaces and gardens located in Isfahan, Shiraz, Kashan and at the seacoast of the Caspian Sea. According to Iranian Islam comprehension, gardens are a paradise where people find peace. Furthermore, gardens reflect Iranian people's culture under the influence of the traditions and customs of Iranians. These gardens have been regarded as a representation of heaven always and presented to people the opportunity of experiencing the desire for eternal life. The influence of religious believes is seen on miniatures and paints that reached today. For instance Cupressus symbolizing death, and flowered trees, defining life and hope, make up the religious philosophy of gardens [3].

The structures were generally positioned in the middle of the gardens or at the highest area in Persian gardens. The highest area where the structures were positioned was called cihannuma. Water features, such as large pools or channels, were designed to create scenery for the structure. In a general sense, Persian garden art was designed by using plain and simple lines. 
The scope of the width or sight opportunity of the area; Persian gardens are generally designed on an axis in the shape of rectangle or square. With the influence of Islam religion, they are enclosed with tall walls and the privacy concept is emphasized. The pathways extend on a single axis and cause a sense of endless paradise for visitors of the gardens and create bliss and joy sensations.

Water use; The most significant component of Persian gardens is water. Pools are placed on the most important main axis of the yard or garden. In case there are multiple pools in the garden, they are connected with each other via conduits and coolness and music effect of water is created. Mainly ceramics of bright and warm colors are used in pools and vitality and movement are added to the location. The environmental conditions of the country played a major role for gardens to be an important living site in Iranian Islam culture and for designating water as an indispensable component. Water was brought from tall, snowy mountains far away via underground channels and was used to create water effects mainly [2]

Symmetry; "Chahar Bag", the four-part formal plan of two channels intersecting one another vertically, made up the foundation of Persian gardens. The use of symmetry in garden designs contributes to achieving balance in the garden The structures in the garden are situated on a symmetrical axis or in the center of the garden. The intermediate point of the symmetrical set up is 'cihannuma' or peak point of the main axis. The symmetrical set up is applied for plant design in the garden as well. Trees and bushes are situated around the hiking areas to emphasize the main axis. Seasonal plants are planted within parquets that are designed symmetrically [3].

Plant materials in Persian garden culture are created for generating shady areas, for fruit-vegetable growing and living area set up. Persian gardens consist of generally tall trees, fruit trees and ornamental plants, especially roses, to create color and scent effects. For creating shady hiking areas in the gardens, trees such as sycamores, willows and elms are planted in the form of an alley on both sides of the pool that is designed as conduits. Cypresses and sycamores take place in the main axis section of the garden. Fruit trees and ornamental plants take place in garden parquets that are designed in the form of partitions.

Persian Gardens located in arid and semi-arid climates while the resource of water is most underground waters like wells, springs and subterranean. Based on water poverty in Iran and arid lands, using underground water channels is treacherous for these areas. Qanats lead water from mountains to villages and fields. This system supplies underground water through a series of shafts that use gravity to bring water to the surface [4].

This Water is the most vital factor for each garden and agriculture field, being in a middle of desert makes this factor more critical for these gardens beside irrigation. The evaporation is the key to the most efficient passive strategy of Persian Gardens, to create thermal comfort and proper area for plants to grow inside of these gardens. Beside the functional usage of water, decorative purpose of water in these gardens cannot be ignored, because the mythical aspects complete the design and performance of these gardens. Thus, water poverty is a risk for these gardens, merging technology with the vernacular passive strategies in these gardens will make them more efficient with higher performance.

The water was used in two forms in Iranian gardens: functional and decorative [4].

Functional aspect of water: Irrigation is a major functional aspect of water in Persian gardens and water is also used for cleaning purposes. Separating the gardens into square or rectangular portions and using straight lines facilitate garden irrigation and lead to less water waste and a timeless design that still functions. Water coming from an aqueduct, a reservoir, or a water-lifting device enters the channels and is distributed throughout the quadrants. Water runs through each quadrant far enough so that plant roots can reach it. Access was allowed or denied by opening or blocking entrance points with mud or stones.

Decorative aspect of water: Persian gardens feature water for its various decorative aspects including jets, fountains, pools, channels and waterfalls in order to achieve higher water volume and symphonies. The qualities of water provide a range of opportunities in gardens. Pools that contain fish or ducks promote plant growth and each of these elements contributes to the subtle water movement. Tanks or channels with fountains are glamorous and captivate the ears; moreover, spray action and the drops falling on the water surface cause pleasant sounds and ripples [4].

\section{CASE Study}

\section{Bagh-e Shahzadeh- Kerman}

Bagh-e Shahzadeh (Fig. 1) is located at a distance of $35 \mathrm{~km}$ southeast of Kerman city and a distance of $6 \mathrm{~km}$ from Mahan Town. It stands on Kerman-Bam roadway near Jupar highlands. It is situated in the plain at the northern skirts of Jupar mountain peak and the western skirt of Pulvar mountain which consists of Cerates lime depositions. Such depositions are important resources of water and occupy a vast area. The large difference of temperatures between day and night is one of the climatic features of this area [5].

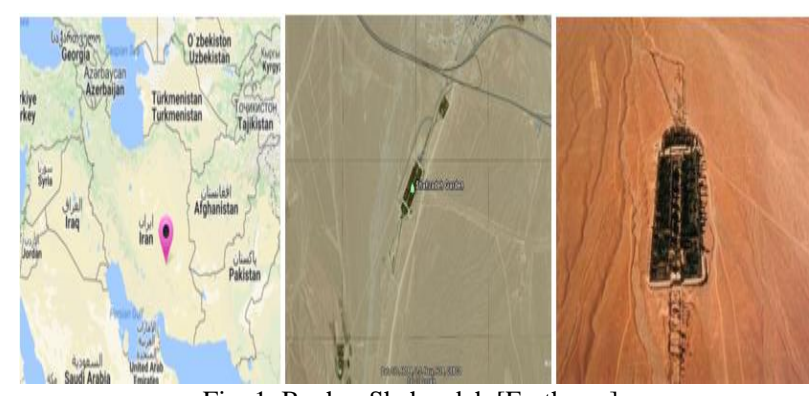

Fig. 1. Bagh-e Shahzadeh [Earth pro].

Bagh-e Shahzadeh (Prince's garden in Persian language) is 5.5 hectares, rectangular shaped with an approximately $4.6 \%$ slope. The garden stands on a vast, open terrain which is encircled by far-off mountains on two sides and a high fence separates it from the harsh environment surrounding it. In particular, high Jupar mountains provide an eye-catching background landscape for the garden [5].

Kerman Province is situated in a low-pressure zone adjacent to tropical region but far from any source of 
moisture production, which result in its scarce rainfall. Due to high variability and irregularity of precipitations, frequent draughts take place influencing negatively provincial water resources. As a result, the presence of springs is among major factors contributing to the formation of mountain villages in Kerman Province because they make underground waters run on the surface. Additionally, they serve as sources of supplying drinking water as well as irrigation of cultivated lands. Approximately, three hundred springs have been counted in the province. Moreover, Kerman Province has a large number of Qantas which have been operating since a long time ago [5].

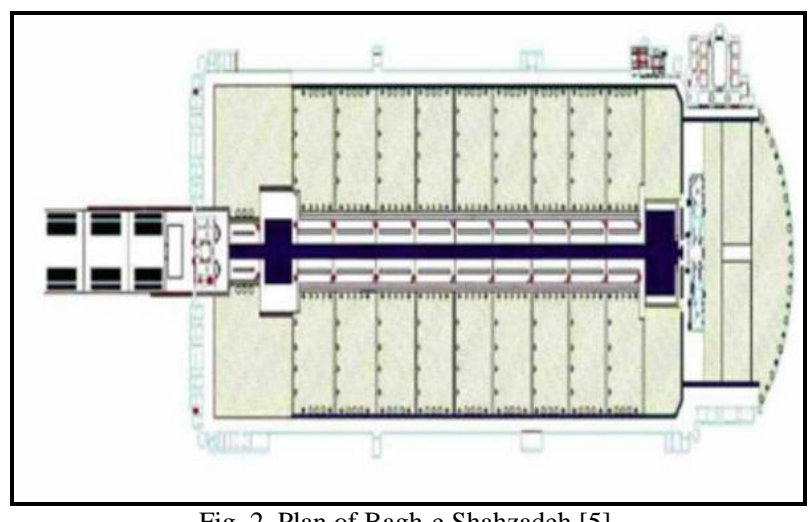

Fig. 2. Plan of Bagh-e Shahzadeh [5].

Water, the vital source of life in this garden, arrives there through its upper section. Main and subsidiary axes and flat Takhts (steps) are irrigated on a regular basis and hence, a rich and unique green field is generated within the gardens. The water arriving to the garden is dispersed longitudinally so that karts and tree linings along walkways are irrigated. At the same time, it uses sharp ground slope as a fundamental condition for Takht gardens and then it flows as a large stream through the primary middle axis of the garden and generates cascades and jets as the main quality element in Bagh-e Shahzadeh [5] (Fig. 3).
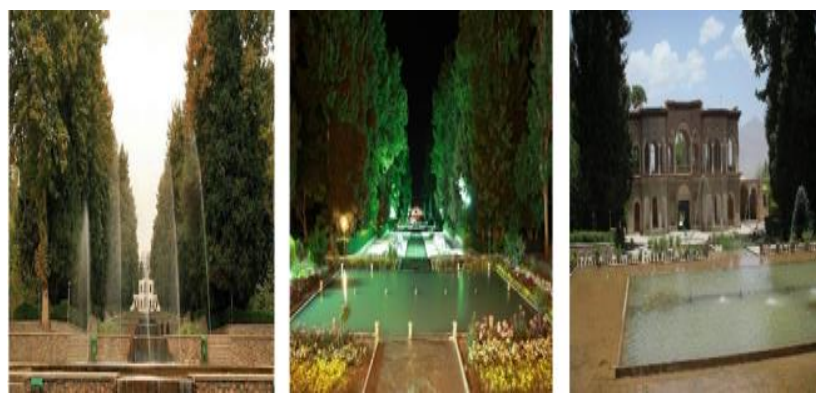

Fig. 3. Water usage in Shahzadeh Garden [5].

There are two pools with a large surface situated at the two ends of the main axis ejaculating jets of water and their noise contributes to the pleasing aura of the garden, and the garden pavilion and the garden entrance opposite the house façade are located on the first Takht.

There is a main pavilion in the upper section of the garden as the only building, functioning as the permanent or temporary dwelling for its owner (Fig. 4). One of the characteristics of Bagh-e Shahzadeh adding more depth to the perspective in comparison to the other gardens is its relatively long length, pleasant landscape and noisy high jets of water playing a relaxing music [5].

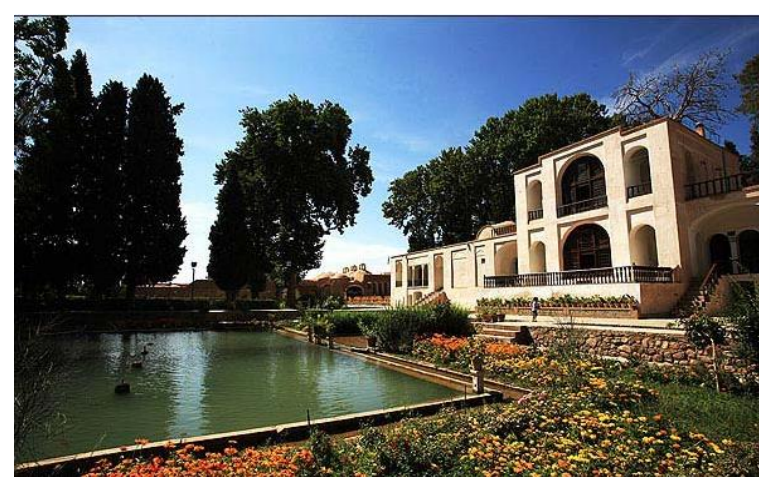

Fig. 4. Use of water in mail pavilion [5].

The principal internal views including water motion, basins and cascades emphasize the axes perpendicular to the main axis. These views and its plant system present inviting internal views of the garden. There are three main water current courses on the middle longitudinal axis alternatively. In this way, the fountains among the large stream and shadow generating trees have formed a lovely aura for walking and relaxing. The garden is separated from the surrounding desert by tall walls near the double longitudinal side axes. The garden grounds are exposed like mirrors by land organization of garden Takht and its layering by Kart surfaces. Thus, the relationship between the viewer and the flat ground improved and the land topography's role intensified in the garden [5].

The axes are emphasized by the water current and pools and at the same time the fountains situated everywhere form cascades that generate transparent surfaces on the ground and reflect other features. The trees cast shadow along the axis and emphasize and improve coordinates of garden configuration. A shaded revitalizing aura is created by the extension of the main axis through the middle of the garden and water current along it. Furthermore, the garden space is defined based on its geometrical system by creating vertical vegetation surfaces with various levels of transparency.

There are two groups of transversal and longitudinal axes that are perpendicular to each other.

A waterway followed the last cascade of the garden opposite the house façade in a distance and joined the main entrance pool outside. There are high jets in the middle of the major entrance pool and the distance between it and the end waterfall. Water currents originating from nearby mountains are the life source in Bagh-e Shahzadeh. Tigran Qanat originates in Jupar highlands and provides the water for this garden. Its current enters the garden from the highest surface and forms its irrigation system. Today, the water is mixed with mud at the upstream for preventing its depositing and wasting and for delivering it to the garden. This is needed more during summer because of water shortage but the water is still wasted immensely.

Irrigation system in Shahzdeh Garden is essentially based on two principles. First, watering garden plants and second, exploiting the entities and qualities that water can create in the garden. Designer of this garden not only has resolved the first problem but also has resorted to unique innovations. Water distribution in transversal and longitudinal paths of garden is in this manner: water current flowing into the garden from the far end of it is divided into five longitudinal branches. Its most major branch is the route superimposed on the main axis of the garden and carries the permanent water 
flow. This route is branched off the large basin located in front of the main building which after passing various Takhts and creating cascades and small basins splashes into the entrance precinct basin. Cascades and water noises play a key role in creating a relaxing atmosphere in the garden. In order to increase this effect, stones were laid beside cascades to boost the water current noise and turbulence.

On either side of this axis along central walkway lines, two water currents flow temporarily from top to bottom in order to irrigate karts and major trees. Two other tops to bottom paths also exist on garden side which are used to irrigate karts as well as lateral row trees. The water flowing on central axis runs permanently and after making cascades and filling basins goes out of the garden from either side of the frontispiece-house pavilion and irrigates the pre-court yard. Then it reaches the remains of a long Chahar Bagh which bypasses the tomb garden and finally goes through the village for irrigation purposes [5].

\section{CONCLUSION}

The architecture extends through the water in ancient Persia and remains calm along it however the water in Islamic period has an applied form in the architecture. Architects attempt to master the nature and maintain its order willingly and draw the water in the architecture based on physical laws and water behavior characteristics and its role, allegory and relationship with humans. Water appears in various geometrical shapes in most buildings and the centralization of architectural unity is achieved in water. Its wavy motion exists in religious concepts and literary arts in our culture. Hence, it is included in our buildings and monuments so that it cannot be practically separated from their shape. Water exists in the center of the palace, garden and so on. In deserts, scarce and life- source water results in the formation of the architecture of water, reservoirs, downstream, Ribats and glaciers, and it manifests itself in other ways.

Water is an example symbolic component of life and was related with many beliefs for the Persians and it also took a central place in the garden owing to its magical power. Water in Persian gardens was used for decoration and in irrigation systems and always opting for the simplest ways from a short distance so that a minimum amount of water is wasted. The water is divided in the garden into squares and rectangles in accordance with the garden's geometrical shape to achieve convenient irrigation. Functional and decorative elements in gardens are generated by water motion through channels, reflections in pools, spraying from jets or fountains, dripping or tinkling or lapping. Thus, meanings are provided including transiency, sense of novelty or the concept of freshness at different temperatures inside the garden. The water is personified by a goddess due to its life-source property, the fertile feature of the garden surrounding it and its cooling feeling it provides. As far as the arid Iranian climate is concerned, water sounds such as rushing, sloshing and splashing make people feel like they are in paradise by creating various water sounds, colors, ripples and shapes.

\section{REFERENCES}

[1] S. M. Ansari, "An investigation into usage and water efficient design for Persian gardens," Master thesis, University of Arizona, December 2015

[2] P. A. Göker and E. Erdoğan, "Islamic gardens," Journal of Tekirdag Agricultural Faculty, vol. 9, 2012, pp. 20-31.

[3] P. Göker and A. Tuna, "An analysis of Persian historical gardens as regards the principles of healing design," Three Pillars of Landscape Architecture; Design, Planning and Management. New Visin. International Conference Proceedings, 2017, pp. 153-160.

[4] J. M. Nejad, H. Azemati, E. Zarghami, and A. Sadeghi, "The role of water in Persian gardens," Open journal of Ecology, July 2017, pp 41-54.

[5] Unesco, "The Persian gardens - Identification of the property," 2011, p. 1106.

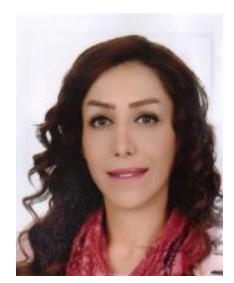

Parsia Goker was born in July 1981 in Iran. She completed her doctoral degree from agriculture faculty, department of landscape Architecture. She is working as assistant professor and also is vice-dean of Art and Design Faculty and Head of Department of Interior architecture and Environment Design in Bilecik Seyh Edebali University, Bilecik, Turkey. Her research interests are historical and cultural landscape, cultural heritage, garden design, Islamic architecture, Persian gardens and Turkish-Anatolian architecture and gardens design, Ottoman Era palace gardens. 